\title{
Trust in a Time of Uncertainty: A Call for Articles
}

\author{
Elise Peterson Lu, MD, PhD'1, Mel L Anderson, MD², Erin Shaughnessy, MD, MSHCM³, Luci K Leykum, MD, MBA, MSc, \\ Daniel B Wolfson, MHSA', Samir S Shah, MD, MSCE7*
}

${ }^{1}$ Paul C Gaffney Division of Hospital Medicine, UPMC Children's Hospital of Pittsburgh, Pittsburgh, Pennsylvania; ${ }^{2}$ Division of Hospital Medicine, University of Colorado, Aurora, Colorado; ${ }^{3}$ Division of Pediatric Hospital Medicine, Children's Hospital of Alabama, Birmingham, Alabama; ${ }^{4}$ Dell Medical School, University of Texas at Austin, Austin, Texas; ${ }^{5}$ Medicine Service, South Texas Veterans Heath Care System, San Antonio, Texas; ${ }^{6} \mathrm{ABIM}$ Foundation, Philadelphia, Pennsylvania; ' Division of Hospital Medicine, Cincinnati Children's Hospital Medical Center, Cincinnati, Ohio.

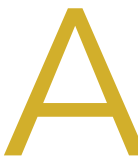

functioning healthcare system requires trust on many levels. In its simplest form, this is the trust between an individual patient and their physician that allows for candor, autonomy, informed decisions, and compassionate care. Trust is a central component of medical education, as trainees gradually earn the trust of their supervisors to achieve autonomy. And, on a much larger scale, societal trust in science, the facts, and the medical system influences individual and group decisions that can have far-reaching consequences.

Defining trust is challenging. Trust is relational, an often subconscious decision "by one individual to depend on another," but it can also be as broad as trust in an institution or a national system. ${ }^{1}$ Trust also requires vulnerability-trusting another person or system means ceding some level of personal control and accepting risk. Thus, to ask patients and society to trust in physicians, the healthcare system, or public health institutions, though essential, is no small request.

Physicians and the medical system at large have not always behaved in ways that warrant trust. Medical research on vulnerable populations (historically marginalized communities, prisoners, residents of institutions) has occurred within living memory. Systemic racism within medicine has led to marked disparities in access and outcomes between White and minoritized communities. ${ }^{2}$ These disparities have been accentuated by the pandemic. Black and Brown patients have higher infection rates and higher mortality rates but less access to healthcare. ${ }^{3}$ Vaccine distribution, which has been complicated by historic earned distrust from Black and Brown communities, revealed systemic racism. For example, many early mass vaccination sites, such as Dodger Stadium in Los Angeles, could only be easily reached by car. Online appointment scheduling platforms were opaque and required access to technology. ${ }^{4}$

Public trust in institutions has been eroding over the past several decades, but healthcare has unfortunately seen the largest decline. ${ }^{5}$ Individual healthcare decisions have also been increasingly politicized; the net result is the creation of laws, such as those limiting discussions of firearm safety or banning gender-affirming treatments for transgender

*Corresponding Author: Samir S Shah; E-mail: Samir.Shah@cchmc.org; Twitter: @SamirShahMD.

Published online first May 24, 2021

Received: May 17, 2021; Accepted: May 17, 2021

(c) 2021 Society of Hospital Medicine DOI 10.12788/jhm.3653 children, that influence patient-physician interactions. This combination of erosion of trust and politicization of medical decisions has been harshly highlighted by the global pandemic, complicating public health policy and doctor-patient discussions. Public health measures such as masking and vaccination have become polarized. ${ }^{6}$ Further, there is diminishing trust in medical recommendations, brought about by the current media landscape and by frequent modifications to public health recommendations. Science and medicine are constantly changing, and knowledge in these fields is ultimately provisional. Unfortunately, when new data are published that contradict prior information or report new or dramatic findings, it can appear that the medical system was somehow obscuring the truth in the past, rather than simply advancing its knowledge in the present.

How do we build trust? How do we function in a healthcare system where trust has been eroded? Trust is ultimately a fragile thing. The process of earning it is not swift or straightforward, but it can be lost in a moment.

In partnership with the ABIM Foundation, the Journal of Hospital Medicine will explore the concept of trust in all facets of healthcare and medical education, including understanding the drivers of trust in a multitude of settings and in different relationships (patient-clinician, clinician-trainee, clinician- or trainee-organization, health system-community), interventions to build trust, and the enablers of those interventions. To this end, we are seeking articles that explore or evaluate trust. These include original research, brief reports, perspectives, and Leadership \& Professional Development articles. Articles focusing on trust should be submitted by December 31, 2021.

Disclosures: The author have no conflicts to disclose.

\section{References}

1. Hendren EM, Kumagai AK. A matter of trust. Acad Med. 2019;94(9):12701272. https://doi.org/10.1097/ACM.0000000000002846

2. Unaka NI, Reynolds KL. Truth in tension: reflections on racism in medicine. J Hosp Med. 2020;15(7):572-573. https://doi.org/10.12788/jhm.3492

3. Manning KD. When grief and crises intersect: perspectives of a Black physician in the time of two pandemics. J Hosp Med. 2020;15(9):566-567. https://doi. org/10.12788/jhm.3481

4. Dembosky A. It's not Tuskegee. Current medical racism fuels Black Americans' vaccine hesitancy. Los Angeles Times. March 25, 2021.

5. Lynch TJ, Wolfson DB, Baron RJ. A trust initiative in health care: why and why now? Acad Med. 2019;94(4):463-465. https://doi.org/10.1097/ ACM.0000000000002599

6. Sherling DH, Bell M. Masks, seat belts, and the politicization of public health. J Hosp Med. 2020;15(11):692-693. https://doi.org/10.12788/jhm.3524 